that an attempt at radical cure should be made at once. Sir Joseph thought it was within the bounds of possibility that a growth of this type might take on a malignant tendency if subjected in a hot climate to continued irritation. The course he advised was steady blistering until complete destruction of all epithelial tissue had taken place both at the seat of trouble and well round it, keeping the sore open and active by the application of savin. This plan of treatment I carried out fully, and produced a couple of large deep ulcers, the two patches which were so near together being treated as one. I kept the sores open for nearly three weeks, and then allowed them gradually to heal, dressing them with carbolised oil ( 1 in 20). The carbolic acid was well borne, and I had the satisfaction of finding the resulting cicatrix firm and flat. The last dressing was applied on March 5th, and since that date Mr. D- has had no symptoms of any return of his trouble. Perfect rest in the horizontal position, with the leg well up, was maintained throughout.

Orchard-street, Portman-square, W.

\section{CASE OF SACCULATED ANEURYSM OF THE DESCENDING THORACIC AORTA OPENING} INTO THE LEFT BRONCHUS.

By C. D'A. COLLINGS, M.A., M.B. Oxon.

THE following case is interesting from the rarity of similar aneurysms in women, and from the difficulty of arriving at a correct diagnosis before the bursting of the sac into the airpassages.

Maria $\mathrm{C}-$, aged forty-eight, a Frenchwoman, of intemperate habits, but without any distinet syphilitic history, was admitted into the hospital on April 26th, suffering from dyspncea. She carried on her trade as a hawker until two or three days previously, when, the difficulty of breathing having increased, she took to her bed.

On admission her temperature was $103.5^{\circ}$, pulse 120 , and respiration 55 ; lips and nails livid; respiration somewhat wheezing; expectoration tolerably copious and frothy, with only a very slight rusty tinge. Examination of the chest revelaled dulness all over the left side, both in front and behind; heart's apex not displaced. Measurement of left side of chest at level of fifth cartilage, $16 \frac{1}{4} \mathrm{in}$. ; of right side, 16 in. Bronchial breathing was heard in the left infraclavicular and over the left scapular regions; over the rest of the left side the respiratory murmur was greatly diminished, but somewhat bronchial in character, expiration being more audible than inspiration ; there was slight bronchophony in the left scapular region. The heart sounds were normal ; no murmur was heard either in front of the chest or behind. Radial pulses and pupils equal.

The elevation of temperature continued for about fifteen days, when it gradually subsided to normal ; the duskiness disappeared; the respiration was reduced to about 20 , and the pulse to 80 . The physical signs remained unaltered, but the heart's apex beat was displaced somewhat outwards and upwards, being felt about half an inch external to and in the nipple line. The patient was feeling much easier, and was allowed to get up a little each day ; she still complained of some pain referred to the lower angle of the left scapula and down the left arm. Some blood-stained serum was drawn from the pleural cavity by a hypodermic syringe; but a day or two later no fluid could be drawn off by the aspirator. On the morning of May 27th the patient got up to have her bed made, and on getting into bed again was seized with a fit of coughing, bringing up about two pints of bright-red blood, which poured from the mouth and nose. When seen five minutes later she was found to be quite dead.

Necropsy.-On opening the thorax, the right lung was found to be quite healthy, but enlarged, encroaching over to the left side. The left lung was found collapsed and utterly airless, the pleural cavity containing about half a pint of fluid. The heart was normal ; there was no valvular disease or hypertrophy. The whole of the arch of the aorta was found to be atheromatous, only small patches remaining of normal appearance. On the anterior part of the descending aorta, as it lay behind the left bronchus, was found a saccular aneurysm, about the size of a horse chesnut, lined with laminated fibrin, the opening into the aorta being about the size of a threepenny-piece. There was an opening from it into the bronchus about the size of a quill ; the sac and part of the bronchus extending to the trachea were filled with clot; the distal part of the bronchus contained no clot, but only blood-stained mucus. There was very little induration of the tissues around the sac. Liver and other organs normal.

Guernsey.

\section{TWO CASES OF RUPTURE OF THE HEART.}

\section{By A. WITHERS GREEN, M.R.C.S., L.R.C.P.}

CASE 1.-E. T. H- aged seventy-seven, a heavy man, went to bed as usual one night in October, 1881. On the servant bringing him in his breakfast next morning, he found him dead in his bed. The deceased was known to be somewhat eccentric; he was said to be subject to fits of some kind, and to have had rheumatism in 1878. He was a revising barrister. A post-mortem examination showed the brain and lungs to be healthy. The heart was dilated and flabby, the aortic valves containing some chalky deposit. The right coronary artery was thickened, and felt like a cord from outside. On stripping it up from the aorta, a recent but ante-mortem clot, an inch long, was reached, and beyond it a much older, tough, adherent clot; further on still was an extravasation of blood through the posterior wall of the right ventricle. There was blood between the muscle of the heart and the visceral layer of the pericardium, and a pint of blood, half of which was clotted, in the pericardial sac. It would seem that the atheroma in the right coronary artery had led to almost complete plugging of the artery, but it was the fresh clot completely occluding the artery which probably caused the rupture.

CASE 2. -W. J. H. W-, aged sixty-six, a well-made man, on May 7th was sitting listening to a debate, as was his wont, in which he never took any part. Suddenly he fell off his seat, was laid flat on the ground by those nearest him, gave a few deep inspirations, and expired. The deceased was a retired engraver, and was believed to have lived a steady life. Three days before his death he complained of pain at his left side, but would see no doctor. At the time of his death he was drinking gin, instead of his usual beverage of malt liquor. On post-mortem examination, the left pupil was found to be dilated, and the muscles of the left side of the face appeared as in facial paralysis. The vessels at the base of the brain were very atheromatous. The heart weighed twenty ounces. The left ventricle, forming the greater part, was much hypertrophied and rather dilated towards the apex. At the apex, on the septal side, was an irregular laceration of the muscular substance running through into the right ventricle, and also outwards into the sub-pericardial fat; both this and the edges of the laceration were infiltrated with blood. The pericardial sac contained about a pint of clotted blood. The valves on both sides were healthy, though the aortic and mitral valves were slightly thickened with atheromatous deposit. The first inch of the aorta was also moderately atheromatous, and the coronary arteries were excessively calcareous, both of them being narrowed in their main trunk The branch running down the anterior aspect, corresponding to the septum and to the laceration, had its coats changed at more than one spot by altered blood-colouring matter of old date. The muscular tissue, notwithstanding the disease of the vessels and the laceration, appeared to be very good; its colour was of a natural deep-red, and it displayed no unnatural softness or fatty change. The cause of death being ascertained, no further investigation was considered necessary as regards other organs.

Medical Mission Work IN Kashmir.-At the hospital at Spinagar 5402 new patients were registered during 1883 and a total of 12978 visits paid. The number of in-patients was 391, the average stay of each of these being twelve days. In the Leper Asylum thirty-two patients wereltreated, seven being operated upon. The financial condition of the institution is satisfactory, and the year ciosed with a considerable balance in hand. Dr. Neve, in his report, states that such diseases as phthisis, pneumonia, pleurisy, rickets, scrofula, and aneurysm, are in Kashmir very rare, almost unknown, notwithstanding cold, poverty, insufficient food and clothing, overcrow ding, and syphilis. 


\section{A}

$$
\text { or }
$$

\section{HOSPITAL PRACTICE, BRITISH AND FOREIGN.}

Nullaantem estalia pro certo noscendi via, nisi quamplarimas et morborum et dissectionum historias, tum aliorum tum proprias collectas habere, et Inter so comparare.-Moreatri De Sed. et Oaws. Mrorb., lib. iv. Procomium.

\section{GUY'S HOSPITAL.}

CASES OF FRACTURE OF THE BASE OF THE SKULL. (Under the care of Mr. BRYANT.)

THE following series of cases of fracture of the base of the skull illustrates some of the more important complications attending this lesion :-

CASE 1. Fracture of Base of Skull; Hemorrhage from Left Ear ; Right Facial Paralysis; Recovery. (From notes by $\mathrm{Mr}$. Hilbers.)-John $\mathrm{C}-$, aged sixty-three, a warrant officer, wasadmitted on Nov, 2nd, 1882. He had been knocked down by a horse and cart, and was brought to the hospital insensible. Soon after admission he became sensible, but seemed dazed and was very sick. There was no superficial wound of the scalp, but there was copious hæmorrhage from the left ear. On the following day he was sensible, but complained of pain in the head and stiffness about the right arm. He was still giddy, and had been sick several times. There was paralysis of the right side of the face. The pupils were equal and acted well to light. Temperature $98^{\circ} 2^{\circ}$, pulse 80. Ordered an ice-bag to the head, and to have five grains of calomel at night. On the 7 th he complained of throbbing pain in the head and pain at the back of the eye. On the 11th he slept and ate well, and the paralysis had almost entirely disappeared. $\mathrm{Oa}$ Dec. 5th he was discharged well, but was advised to keep quiet for five or six weeks.

CASE 2. Fracture of the Anterior Fossa; Subconjunctival and Nasal Hamorrhage; Separation of Lower Epiphysis of Radius; Death; Necropsy. (From notes by Mr. F. Knaggs.) -James $\mathrm{H}-$, aged twelve, was admitted on February 24th, 1883. He was sliding down the balustrade of a warehouse, when he fell from the third floor. On admission, at 2 P.M., he was quite insensible ; pupils dilated and unequal, the left being the larger; no bleeding from the ears, but some from the nose and mouth (he fell upon his face) ; respiration irregular, but not of the Cheyne-Stokes character. The left evelid was much swollen, and the lower lid was of a bluish-black tint. There was a slight puffy swelling of the anterior half of the left temporal fossa. There was, in addition, the typical displacement of a Colles' fracture of the lower end of the radius; crepitus not felt. The right knee was slightly flexed and passed over the front of the left leg. There was very little enlargement of the kneejoint, but fluid could be felt on both sides of the patella. At 4 P.M. the right pupil contracted and dilated in a rhythmical manner without reference to light. At 5 P.M. both pupils contracted and dilated alternately; both eyes turned to the right, and then a twitching of the whole eyeball occurred, and the whole eye was markedly directed outwards, but occasionally there was a return movement of the eyes to their proper position. On the left side the subconjunctival hæmorrhage was very distinct. The eyelids were difficult to open on account of swelling. Respiration 28; snoring as in normal sleep. Well-marked anchylosis of right knee. At 11 P.M. the skin was bathed in perspiration; loud rhonchi could be heard all over the chest; no spasms or twitching.-Feb. 25th: Restless ; respiration stertorous and regular. At 1 P.M. the respiration was rapid and irregular; limbs perfectly flaccid. -26 th : The patient died at 12.5 P.M. The temperature rose more or less regularly from $966^{\circ}$ on $\mathrm{Feb}$. $24 \mathrm{th}$ to $1054^{\circ}$ on the $26 \mathrm{tb}$, the time of his death.

Necropsy.-There was a contusion about the left orbit, and a fracture of the left orbital plate of the frontal bone. No injury to the brain was observed. There was a fracture of the styloid process of the vena, and separation of the lower epiphysis of the radius backwards. The organs were healthy, with the exception of a slight bæmorrhagic effusion below the capsule and under the suif $i c e$ of the liver. There was no hæmorrhage into the left orbit. The fracture ex tended obliquely backwards and inwards on the orbital plate of the frontal bone to the cavernous sinus, rupturing the ethmoidal vessels, as the ethmoidal bone was seen to be implicated in the sinus. No inflammation in the membranes existed.

CASE 3. Fractured Base; Crushed Mastoid Process; Escape of Cerebro-spinal Fluid for eight days from Ear Fractured Lower Jaw; Recovery. (From notes by Mr. Ironson.) - Walter Edward $\mathrm{C}-$, aged six, was knocked down by a light van, the wheel of which went over his head. On admission, on April 20th, 1883, the child was found to have a large wound on the left side of the head, and the head and face were much bruised and abraded. There was a sero-sanguineous discharge from the ear. No paralysis existed, and the patient was quite conscious. There was a great depression on the left mastoid process, where the bone had been crushed, and also a considerable contusion about the left angle of the jaw. The right side of the neck and face was much swollen, and the right eyelids were com pletely closed up. On the 24 th the discharge from the ear still continued, but the swelling of the face had subsided The right eyelid was open and the pupils dilated, acting however, equally, though sluggishly. On the 27 th the child was much brighter, and the wound was healing up. A small pocket of pus was opened by incision at the apex of the mastoid process. On the 28 th the flow of cerebro-spinal fluid ceased. On May 3rd the patient's face was much swollen on the left side, about the lower jaw. The dresser thought he heard crepitus near the symphysis. On the 8th there was considerable fluctuation observed near the fracture. Next day the swelling over the lower jaw was incised, and some white pus escaped. On the 21 st there was some purulen discharge from the left ear, but the wounds were doing well. Oa June 16th the patient was discharged.

CASE 4. Fractured Base of Skull; Scalp Wound; Facial Paralysis on Left, and subsequently on Right, Side; Mastoid Abscess; Incision; Prolonged Incoherence; Recovery. (From notes by Mr. Humphreys.) - Mary Ann $\mathrm{K}-$ - aged twenty. four, was admitted on Dec. 5th, 1882 . She was a drunken and bad character. On the evening of the 3 rd she fell into a cellar, and was picked up and left to lie upon the floor all night. Next morning she was found to have bled a good deal, and to have been sick. On the evening of the 5th, as she had not recovered consciousness, she was taken to the hospital. On admission she was found to be collapsed and pulseless. Brandy was injected, which revived her, but did not restore consciousness. She had a scalp-wound to the left of the occipital protuberance of a punched-out appear ance. There was slight left facial paralysis. She had a bruise on the chin and several bruises on her body. Her right pupil was larger than the left. She had perfect move ment of her extremities. She was sick on admission, but not afterwards. Ordered iced milk, and five grains of $\mathrm{c}$ llomel at once. On the following morning she was still unconscious, and fluid was escaping from the ear. Her face turned to the right, and resumed that position if moved. On Dec. 7 th the paralysis of the face was more marked, but next day she became half conscious. On the 11 th a great deal o pus and fluid escaped from the left ear. On the 12th she became very noisy. Two days later a slight fluctuating swelling appeared anterior to the ear. Above and below the mastoid process were two other swellings, and a third behind the ear, and discharging through it. On the 20th the patient was able to talk well. Two days later a great deal of bad smelling discharge escaped from the left ear. On the 27 th there was less discharge from the ear, and the swelling in front of it had subsided. On Jan. 2nd the skin had become red over and around the ear; and on the 5 th some necrosed bone could be felt in the abscess behind the ear. There was a slight rash on the face and forehead. On the 9 th there was still some paralysis of the right side of the face. It was stated that the woman had been rather "silly" for the last few days, continually giggling and making disconnected remarks when spoken to. 0 the $13 \mathrm{th}$, however, she seemed more collected. There seemed to be complete paralysis of the right side. On the 16 th the patient had more control of the right half of the face. Some blood-stained discharge came from the abscess behind the ear. On the 22 nd the patient was rather cyanotic. She complained of hunger and seemed more sensible 0 Feb. 17 th the woman went out, still half foolish, the wound behind the ear continuing to discharge. The occipital wound was healed, and in gentral heal' $h$ she was improved. 